\title{
ESTUDO COMPARATIVO DE TESTES SOROLÓGICOS NO DIAGNÓSTICO IMUNOLÓGICO DA NEUROCISTICERCOSE
}

\author{
Carmen Silvia de Melo PIALARISsI (1), Adelaide José Vaz (1), Ana Maria Carvalho de SOUza (1), \\ Paulo Mutulko Nakamura (1), Eide Dias Camargo (1), Marcos Vinicius da silva (2) \& \\ Mirthes UEDA (1)
}

\section{R E S U M O}

Estudamos comparativamente quatro técnicas imunológicas para o diagnóstico da neurocisticercose (NC), utilizando líquido cefalorraquiano (LCR) como espécime clínico: as reações de fixação de complemento (RFC), hemaglutinação passiva (RHA), imunofluorescência inđireta (RIF) e teste imunoenzimático ELISA Foram ensaiadas 125 amostras de LCR de pacientes com NC comprovada e 94 amostras de LCR do grupo controle (60 de pacientes com quadros clínicos neurológicos diversos e 34 de pacientes supostamente normais). Os índices de sensibilidade e especificidade obtidos para os testes foram, respectivamente, de $48,0 \%$ e $90,4 \%$ para a $\mathrm{RFC} ; 88,8 \%$ e $96,8 \%$ para a $\mathrm{RHA}$; 87,2 e $98,9 \%$ para a RIF e $97,6 \%$ e $98,9 \%$ para o teste ELISA. A diferença significativa $(p<0,05)$ observada entre os testes permite concluir que o melhor teste para o diagnóstico de NC foi o teste ELISA seguido das reaçóes de HA e IF.

UNITERMOS: Neurocisticercose; Líquido cefalorraquiano; Imunodiagnóstico da neurocisticercose.

\section{N T R O D U G $\tilde{A}$ O}

A neurocisticercose humana destaca-se entre as afecções do sistema nervoso central causadas por parasitas, pela elevada freqüência e principalmente pela gravidade das le, sões que acarreta, constituindo problema de saúde pública de interesse em nosso meio.

A infestação do sistema nervoso e seus envoltórios pelo Cysticercus cellulosae, - neurocisticercose $\longrightarrow$ pode determinar alterações no líquido cefalorraquiano indicadoras da reação inflamatória. LANGE, em $1940^{12}$ conceituou a "síndrome liquórica da neurocisticercose", caracterizada fundamentalmente pela ocorrência de pleocitose, eosinofilorraquia e anticorpos específicos detectados através da reação de fixação de complemento, Outros autores têm encontrado baixa sensibilidade e limitada especificidade para esta reação quan. do aplicada em soro ou líquido cefalorraquiano $7,8,21,24$

Com o desenvolvimento de métodos imunológicos mais sensíveis e específicos, as técnicas sorológicas têm sido utilizadas no diagnóstico đa neurocisticercose com maior confiabilidade ${ }^{14}$.

A reação de hemaglutinação passiva, empregada mais freqüentemente no soro, tem apresentado resultados variáveis $3,16,17,20$. A reação de imunofluorescência indireta utilizando fragmentos 15 ou cortes histológicos ${ }^{10}$ de Cysticercus cellulosae, tem sido empregada em

(1) Seção de Sorologia do Instituto Adolfo Lutz de São Paulo, SP., Brasil.

(2) Seção de Sorologia do Instituto- Adolfo Lutz e Hospital Emilio Ríbas, São Paulo, SP., Brasil.

Enderep̧o para correspondência: Dra. Carmen S. de Melo Pialarissí. Instituto Adolfo Lutz. Seçäo de Sorologia. Av. Dr. Arnaldo, 355. CEP 01246. São Paụlo, SP., Brasil. 
PIALARISSI, C. S. de M.; VAZ, A. J.; SOUZA, A. M. C. de; NAKAMURA, P. M.; CAMARGO, E. D.; SILVA, M. V. \& UEDA, M. - Estudo comparativo de testes sorológicos no diagnóstico imunológico da neuroeisticercose. Rev. Inst. Med. trop. São Paulo, 29:367-373, 1987.

soro ou líquido cefalorraquiano com bons resultados $1,2,10,13,15$. Recentemente, o teste imunoenzimático ELISA (Enzyyme-Linked Immunosorbent Assay) vem sendo aplicado ao diagnóstico da neurocisticercose por apresentar alta sensibilidade e especificidade $5,6,14,19$.

Considerando que a resposta imune na neurocisticercose, com produção de anticorpos específicos freqüentemente se restringe às estruturas que circundam o parasita ${ }^{18,22}$, estudamos o comportamento de diferentes técnicas imunológicas, avaliando sua eficiência na deteção desses anticorpos no líquido cefalorraquiano.

\section{MATERIAL E METTODOS}

\section{Antígenos:}

a. Extrato Antigênico Salino Total (ST): o antígeno ST foi utilizado nas reações de $\mathrm{ij}$ xação de complemento (RFC), hemaglutinação passiva (RHA) e no teste ELISA tendo sido preparado conforme metodologia descrita por COSTA 5 . O extrato antigênico obtido foi liofilizado em alíquotas de $1 \mathrm{ml}$ e armazenado a $4^{\circ} \mathrm{C}$. A sua earacterização foi feita quanto às concentrações proteica pelo métođo de BRADFORD ${ }^{4}$ e polissacarídica pelo método da antrona ${ }^{25}$.

b. Antígeno Particulado: $o$ antígeno de partículas de cisticercos foi utilizado fixado a lâmiņas de microscopia para a reação de imunofluorescência indireta (RIF), e foi preparado segundo MACHADO e cols. ${ }^{15}$, com algumas modificações. Os cisticercos lavados e congelados foram secos em dessecador à temperatura ambiente. $O$ material foi triturado em gral e peneirado em tamis de abertura 0,297 mm, "tyler" 48 (Granutest, Brasil). Os fragmentos tamisados foram lavados em etanol (Merck, Brasil) por três vezes, e novamente lavados em acetona bidestilada. As partículas obtidas foram secas em dessecador a vácuo por 24 horas e então ressuspensas em solução salina tamponada com fosfatos, PBS pH 7,2 (Fosfatos 0,01M-NaCl 0,14M) na proporção de $1 \mathrm{mg}$ para $20 \mathrm{ml}$. Após rápida decantação das partículas maiores, o sobrenadante foi distribuído em lâminas de microscopia, cerca de 40 partículas por campo de $400 \mathrm{X}$. As lâminas, após secagem a $37^{\circ} \mathrm{C}$, foram conservadas a $-20^{\circ} \mathrm{C}$, embrulhadas uma a uma.

2. Amostras de líquido cefalorraquiano (LCR): foram ensaiadas 125 amostras de LCR de par cientes com neurocisticercose comprovada. O grupo controle estudado foi constituído por 34 amostras de LCR de indivíduos supostamente normais e por 60 amostras de LCR de pacientes com outros quadros clínicos neuroló gicos, mas isentos de cisticercose (meningites 38; neurossifilis 13; tumores 4; hidrocefalia 2; cefaléia 2; acidente vascular cerebral 1).

\section{Testes sorológicos:}

a. Reação de Fixação de Complemento (RFC): foi empregada a microtécnica da RFC utilizando o antígeno ST, de acordo com a metodologia descrita por FERREIRA e cols. ${ }^{7}$, com modificações nos volumes. Os LCR foram diluídos em placas de microtitulação de poliestireno (Inlab, Brasil) de fundo em $\mathrm{U}$, na razão 2 a partir de $1: 2$, volume final de 0,05 $\mathrm{ml}$, em solução salina contendo íons Cálcio e Magnésio ( $\mathrm{NaCl} 0,15 \mathrm{M} ; \mathrm{CaCl}_{2} 0,15 \mathrm{mM} ; \mathrm{MgCl}_{2}$ $0,5 \mathrm{mM}$ ). A cada cavidzde da placa adicionou-se $0,025 \mathrm{ml}$ de antígeno diluído segundo seu título na meśma solução, e $0,05 \mathrm{ml}$ de soro normal de cobaio (complemento) contendo 5 unidades hemolíticas 50\%. Após 1 hora a $37^{\circ} \mathrm{C}$ foi adicionado o sistema hemolítico (hemácias de carneiro a $1,4 \%$ sensibilizadas com uma unidade exata de hemolisina produzida em coelho), $0,025 \mathrm{ml}$ por cavidade, e a placa foi incubada por 30 minutos a $37^{\circ} \mathrm{C}$ e 1 hora à temperatura ambiente, após o que foil feita a leitura.

b. Reação de Hemaglutinação Passiva (RHA): hemácias de carneiro a 5\% foram sensibilizadas com o extrato antigênico ST, pela metodologia descrita por IMAI e cols ${ }^{11}$, ficando o reagente de uso a $0,5 \%$, A reação foi realizada em placas de microtitulação de poliestireno (Inlab, Brasil), de fundo em V. As amostras de LCR foram diluídas em duas séries de cavidades da placa, na razão 2, a partir de 1:1, em volume de 0,025 ml, em PBS pH 7,2 contendo $0,1 \%$ de soroalbumina bovina (Difco, USA). A uma das séries adicionou-se $0,025 \mathrm{ml}$ de hemácias sensibilizadas e à outra igual volume de hemácias-controle. A placa 
PIALARISSI, C. S. de M.; VAZ, A. J.; SOUZA, A. M. C. de; NAKAMURA, P. M.; CAMARGO, E. D.; SILVA, M. V. \& UEDA, M. - Estudo comparativo de testes sorológicos no diagnóstico imunológico da neurocisticercose. Rev. Inst. Med. trop. São Paulo, 29:367-373, 1987

foi agitada e deixada em repouso à temperatura ambiente por 2 horas, e então foi realizada a leitura.

c. Reação de Imunofluorescência Indireta (RIF): a RIF foi realizada segundo a técnica de MACHADO e cols. ${ }^{15}$, sendo empregado $o$ conjugado anti-gamaglobulina humana-isotiocianato de fluoresceína (Instituto Adolfo Lutz, lote 33 ).

d. Teste imunoenzimático, ELISA: placas de poliestireno de fundo em $U$ foram sensibilizadas com o antígeno ST, diluido conforme o título em solução tamponada carbonato-bicarbonato ( $\mathrm{Na}_{2} \mathrm{CO}_{3}$ 0,02M; $\mathrm{NaHCO}_{3} 0,03 \mathrm{M} ; \mathrm{pH}$ 9,6), no volume de $0,1 \mathrm{ml}$ por cavidade. Após 18 horas a $4^{\circ} \mathrm{C}$, as placas foram lavadas três vezes em PBS pH 7,4 (NaCl 0,13M; fosfatos $0,02 \mathrm{M}$ ) contendo $0,05 \%$ de Tween-20 (Sigma, USA) - PBS-T. A cada cavidade da placa adicionou-se 0,1. $\mathrm{ml}$ das amostras de LCR, puro e suas diluições na razão 2, em PBS-T contendo $0,5 \%$ ide gelatina (Difco, USA), e a placa foi incubada por 45 minutos a $37^{\circ} \mathrm{C}$. Após três lavagens, adicionou-se $0,1 \mathrm{ml}$ do conjugado, anti-IgG humana-fosfatase alcalina (Sigma Chem. Co., USA) diluído a 1:1600 em PBSTG. A placa foi submetida a novo ciclo de incubação e lavagens e a cada cavidade adjcionou-se $0,1 \mathrm{ml}$ da solução cromógena (p-nitrofenil-fosfato dissódico em solução de dietanolamina $1 \mathrm{M}$, pH 9,8 , na proporção de $1 \mathrm{mg}$ / mi) e a placa foi incubada por 30 minutos a $37^{\circ} \mathrm{C}$. A reação enzimática foi interrompida pela adição de $0,05 \mathrm{ml}$ de $\mathrm{NaOH} 2 \mathrm{M}$ e a reatividade avaliada em espectrofotômetro para leitura automática de placas (Titertek Multiskan, Flow Lab., USA), em comprimento de onda de $405 \mathrm{~nm}$.

4. Análise Estatística: a média geométrica dos títulos foi calculada com os títulos codificados pela fórmula $\log _{2}\left(2^{n} / 2\right){ }^{23}$. Para o estudo comparativo dos testes sorológicos foram analisados os indices estatísticos 9 , e aplicado 0 teste $Q$ de Cochran ${ }^{26}$.

\section{RESULTADOS}

As concentrações protéica e polissacarídica do extrato antigênico salino total (ST), obtido de 200 cisticercos em volume final de $20 \mathrm{ml}$, foram respectivamente de $6,1 \mathrm{mg} / \mathrm{ml}$ e $5,2 \mathrm{mg}$ / ml.

A atividade antigênica do antígeno ST foi avaliada por titulação em bloco, frente a ifquidos cefalorraquianos padrões positivo e negativo, para determinação das concentraçōes a serem utilizadas nas reaçōes de fixação de complemento (RFC), de hemaglutinação passíva (RHA) e teste imunoenzimático (ELISA). Na RFC foi obtida a concentração antigênica ótima de $40 \mu \mathrm{g}$ por cavidade da placa. A concentração de $30 \mu \mathrm{g} / \mathrm{ml}$ foi escolhida para a sensibilização das hemácias utilizadas na RHA, como o reagente de uso é diluído 10 vezes, para cada mililitro de hemácias utilizamos $3 \mu \mathrm{g}$ de proteina antigênica. Na figura 1 são apre. sentados os resultados do teste ELISA para os líquidos cefalorraquianos, padrões positivo e negativo, diluídos na razão 2 , a partir de 1:1, e o antígeno ST nas concentraçōes de 5, 10, 20 e $40 \mu \mathrm{g} / \mathrm{ml}$. Foram consideradas po. sitivas as diluições com densidades ópticas (DO) iguais ou maiores que 0,100 ("cut off"). A concentração de $10 \mu \mathrm{g} / \mathrm{ml}$ ou. $1 \mu \mathrm{g}$ por car vidade foi escolhida para a sensibilização das placas.

$\mathrm{Na}$ tabela 1 são apresentados os resultados dos testes sorológicos para as amostras de LCR dos dois grupos estudados: pacientes com neurocisticercose e grupo controle. As distribuições da frequiência dos títulos das 125 amostras de LCR dos pacientes com neurocis. ticercose são apresentadas na figura 2 . $\mathrm{Na}$ tábela 2 são apresentadas as médias geométricas desses títulos (MGT).

A sensibilidade (S) expressa como porcentagem de positividade e a especificidade (E) expressa como porcentagem de negatividade, com os respectivos intervalos de confiança de 95\% de probabilidade, obtidas para os testes realizados, são apresentadas na tabela 3 . $O$ Indice de Youden ( $\mathbf{S}+\mathbf{E - 1}$ ) foi calculado para cada teste, e é apresentado na mesma ta. bela.

Para avaliação da concordância entre os testes, os resultados das 219 amostras de LCR estudadas, foram classificados como reagentes e não-reagentes e analisados comparativamente. Os índices de co-positividade; connegativi. dade e concordância das reações são apresen. tados na tabela 4. 
PIALARISST, C. S. de M.; VAZ, A. J.; SOUZA, A. M. C. de; NAKAMURA, P. M.; CAMaRGo, E. D.; SHVA, M. V. \& UEDA, M. - Estudo comparativo de testes sorológicos no diagnóstíco imunológico da neurocisticercose. Rev. Inst. Med. trop. São Paulo, 29:367-373, 1987.
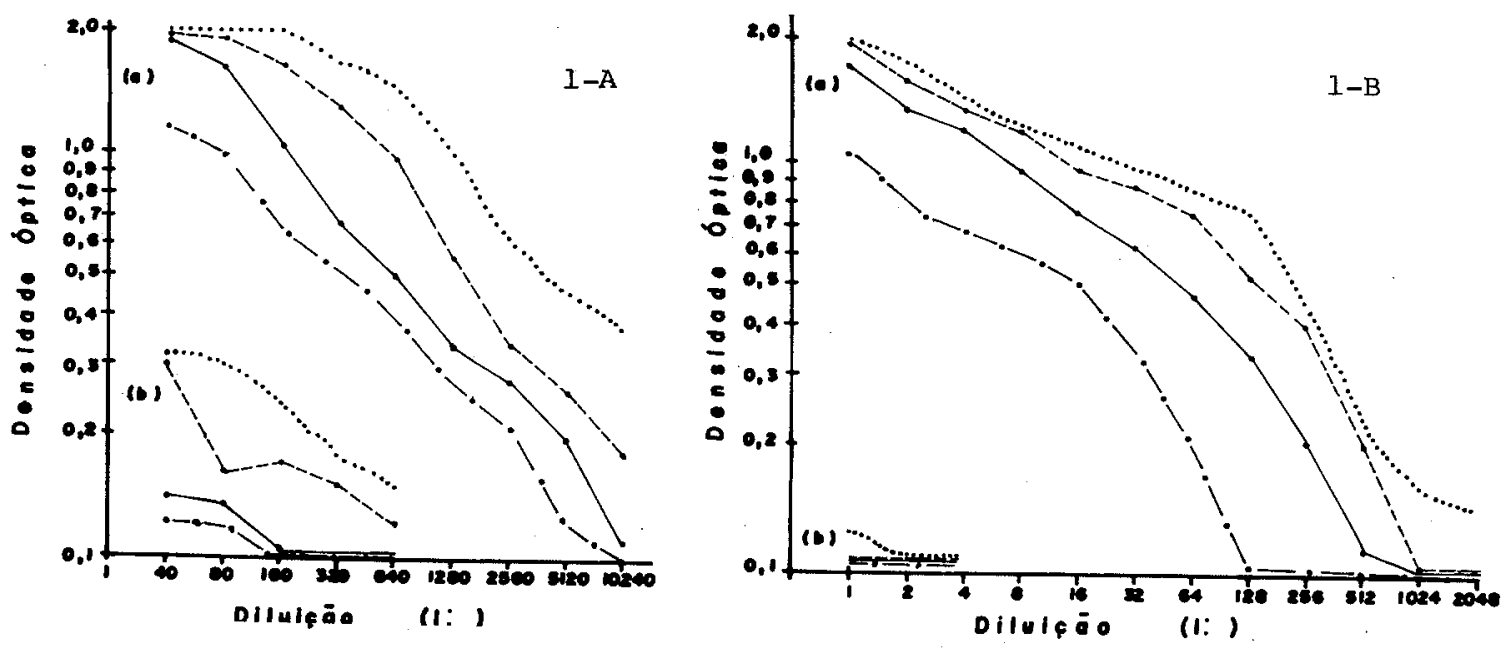

Fig. 1 - Densidades ópticas obtidas para as diluiçóes dos soros (1-A) e líquidos cefalorraquianos (1-B) para padrões positivo (a) e' negativo (b) no teste EurSA, utilizando extrato salino total de Cysticercus cellulosae nas concentraçбęs do $f^{5} \mu \mathrm{g} / \mathrm{ml}(-.,-), 10 \mu \mathrm{g} / \mathrm{ml}(\longrightarrow), 20 \mu \mathrm{g} / \mathrm{ml}(-\longrightarrow)$ e $\left.40 \mu \mathrm{g} / \mathrm{ml} \quad \ldots \ldots\right)$.

T A B E I A I

Distribuiçăo dos líquidos cefalorraquianos dos grupos de pacientes com neurocisticercose (a) e controle. (b), segunda teste sorológico

\begin{tabular}{|c|c|c|c|c|c|c|c|c|c|c|c|c|c|c|c|c|c|c|}
\hline TESTE & GíTLLOS & NR & 1 & 2 & 4 & 8 & 16 & 32 & 64 & 128 & 256 & 512 & 1024 & 2048 & 4096 & 8192 & $>8192$ & TOTAL \\
\hline \multirow[t]{2}{*}{$\mathrm{RFC}^{*}$} & a & 55 & - & 17 & 13 & 16 & 6 & 6 & 1 & - & - & - & 1 & - & - & - & - & 115 \\
\hline & b. & 85 & - & - & 1 & - & - & - & - & - & - & - & - & - & - & - & - & 86 \\
\hline \multirow{2}{*}{ RHA } & & 14 & - & 12 & 11 & 13 & 13 & 12 & 13 & 15 & 7 & 3 & 4 & 5 & 2 & - & 1 & 125 \\
\hline & b & 91 & - & 2 & 1 & - & - & - & - & - & - & - & - & - & - & - & - & 94 \\
\hline \multirow{2}{*}{ RIF } & & 16 & 20 & 16 & 21 & 14 & 13 & 9 & 10 & 4 & 1 & - & - & 1 & - & - & - & 125 \\
\hline & b & 93 & 1 & - & - & - & - & - & - & - & - & - & - & - & - & - & - & 94 \\
\hline \multirow[t]{2}{*}{ ELISA } & $\mathbf{0}$ & 3 & - & 2 & 2 & 2 & 8 & 9 & 17 & 13 & 12 & 21 & 7 & 8 & 12 & 4 & 5 & 125 \\
\hline & b & 93 & - & - & 1 & - & - & - & - & - & - & - & - & - & - & - & - & 94 \\
\hline
\end{tabular}

\section{DISCUSAa}

Foram estudadas as reações de fixação de complemento (RFC), hemaglutinação passiva (RHA) e o teste imunoenzimático ELISA, utilizando extrato antigênico salino total (ST), e a reação de imunofluorescência indireta (RIF) utilizando como antígeno partículas de cisticercos fixadass a lâminas, para pesquisa de anticorpos anti-Cysticercus cellulosae em líquido cefalorraquiano.
A avaliação da atividade antigênica do extrato ST nas reações, demonstrou seu bom rendimento, que ao lado da facilidade de preparação e bom desempenho com relação a especificidade, indicam-no para o preparo de reagentes em larga escala.

$\mathrm{Na}$ figura 1 foram apresentadas as distribuições dos títulos obtidos nos testes para as 125 LCR de pacientes com neurocisticercose. Os maiores títulos foram observados no 
PLALARISST, C. S. de M.; VAZ, A. J.; SOUZA, A. M. C. de; NakaMURA, P. M.; CAMARGO, F. D.; SHLVA, M. V. \& UEDA, M. - Estudo comparativo de testes sorológicos no diagnóstico imunológico da neurocisticercose.
Inst. Med. trop. São Paulo, 29:367-373, 1987.

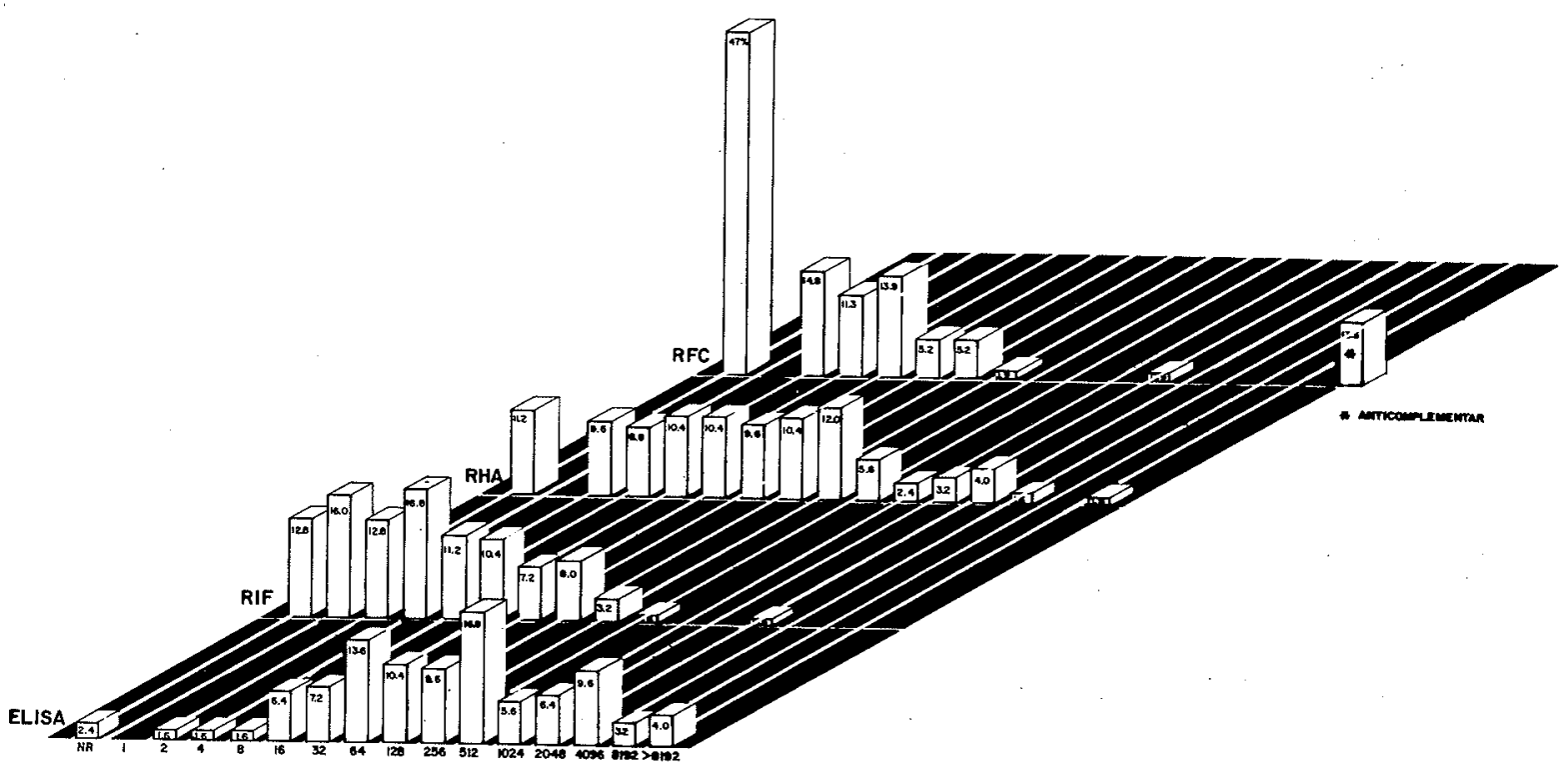
Fig. 2 - Frequî́ncia $(\%)$ dos títulos de 125 liquidos cefalorraquianos de pacientes com neurocisticercose nos testes
sorológicos.

T A B E I A II

Média Geométrica dos títulos dos liquidos cefalorraquianos dos pacientes com neurocisticercose, segundo teste sorológico

\begin{tabular}{l|c|c|l|l}
\hline TESTE & RFC * & RHA & RIF & ELISA \\
\hline MGT & 1,9 & 5,1 & 23,6 & 238,9 \\
\hline
\end{tabular}

* excluíoas as amostras anticomplementares

T A B E L A III

Sensibilidade, especificidade com os respectivos intervalos de confiança (IC) e indice de Youden, segundo teste sorológico realizado no líquido cefalorraquiano

\begin{tabular}{|c|c|c|c|c|c|}
\hline \multirow{2}{*}{ TESTE } & \multicolumn{2}{|c|}{ SENS:LLIDAOE } & \multicolumn{2}{|c|}{ ESPECIFICIOADE } & \multirow[b]{2}{*}{ YOUDEN } \\
\hline & $\frac{\text { mownos }}{\text { rotal }}$ & 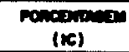 & $\frac{\text { FonTIVOS }}{\text { ToTAL }}$ & 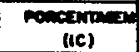 & \\
\hline mFC & $\frac{55}{125}$ & $\begin{array}{c}48,0 \\
(39,0-57,0)\end{array}$ & $\frac{85}{94}$ & 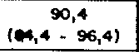 & 0,38 \\
\hline RHA & $\frac{111}{125}$ & 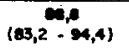 & $\frac{9 !}{94}$ & $\begin{array}{c}96,8 \\
(93,2-100) .\end{array}$ & 0,86 \\
\hline RIF & $\frac{109}{125}$ & $\begin{array}{c}67,2 \\
(81,2-93,2)\end{array}$ & $\frac{93}{94}$ & $\begin{array}{c}98,9 \\
(96,7-100)\end{array}$ & 0,86 \\
\hline ELISA & $\frac{122}{125}$ & $\begin{array}{c}97,6 \\
(94,9-100)\end{array}$ & $\frac{93}{94}$ & $\begin{array}{c}98,9 \\
(96,7-100)\end{array}$ & 0,96 \\
\hline
\end{tabular}

teste ELISA, o que é confirmado pelas MGTs obtidas (tabela 2).

O comportamento dos testes, quanto às sensibilidade e especificidade, tabela 3, sugere que sejam empregadas técnicas mais sensíveis para o diagnóstico da neurocisticercose, quando se estuda o líquido cefalorraquiano. A RFC apresentou a mais baixa sensibilidade (48\%),
T A E E L A IV

fndices de co-positividade, có-negatividade e concordância entre os testes

\begin{tabular}{|c|c|c|c|}
\hline ESTES & co-rosttivines & COMTEATVIDAOE & comcomincia \\
\hline $\begin{array}{l}\text { ELISA } \\
\text { RMA }\end{array}$ & 0,91 & 0,98 & $.0,94$ \\
\hline $\begin{array}{c}\text { Lisa } \\
\text { nIf }\end{array}$ & 0,89 & 0,99 & 0,93 \\
\hline $\begin{array}{c}\text { Elisa } \\
\text { RFC } \\
\end{array}$ & 0,53 & 0,99 & 0,73 \\
\hline $\begin{array}{l}\text { nna } \\
\text { Rif }\end{array}$ & 0,91 & 0,94 & 0,93 \\
\hline$\underset{\text { RFc }}{\text { RHA }}$ & 0,58 & 0,99 & 0,78 \\
\hline$\underset{\text { nIFc }}{\text { nIF }}$ & 0,58 & 0,98 & 0,78 \\
\hline
\end{tabular}

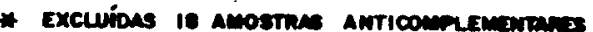

inferior a obtida por REIS-FILHO e culs. ${ }^{24}$. que observaram $\mathbf{7 0 \%}$ de positividade, utilizan. do antígeno de cisticercos tratados com acetona, A especificidade da RFC $(90,4 \%)$ foi considerada boa e, se excluirmos as oito amostras do grupo controle com resultado prejudicado pela anticomplementariedade, a especificidade calculada seria de $98,9 \%$, o que está de acordo com dados de literatura $7,8,21$. A anticomplementariedade de 18 amostras das 219 estudadas $(8,2 \%)$ não era esperada, e poderia ser explicada pelas ligeiras xantocromia e tur. 
PIALARISSI, C. S. de M.; VAZ, A. J.; SOUZA, A. M. C. de; NAKAMURA, P. M.; CAMARGO, E. D.; SILVA, M. V. \& UEDA, M. - Estudo comparativo de testes sorológicos no diagnóstico imunológico da, neurocisticercose. Rev. Inst. Med. trop. São Paulo, 29:367-373, 1987.

vação dessas amostras, presentes mesmo após centrifugação.

A RHA apresentou sensibilidade e especificidade $(88,8 \%$ e $96,8 \%)$ muito melhores que os obtidos por BIAGI e cols: ${ }^{3}$, de $10 \%$ de positividade no estudo da RHA aplicada a LCR de pacientes com neurocisticercose. Nossos resultados também foram superiores aos de MARTINEZ-CAIRO e cols. ${ }^{17}$, que obtiveram sensibilidade de $68 \%$ estudando LCR previamente concentrado cinco vezes.

A RIF também resultou em bons índices de sensibilidade e especificidade, respectiva. mente de $87,2 \%$ e $98,9 \%$, comparáveis aos já descritos para a reação realizada no LCR $1,2,10,13$. Contudo, no nosso estudo a RIF comportouse muito melhor que a $\mathrm{RFC}$, ao contrário do que LIVRAMENTO ${ }^{13}$ e BASSI e cols. ${ }^{2}$ haviam descrito para as duas reações.

O teste imunoenzimático ELISA apresentou alta sensibilidade $(97,6 \%)$ e especificidade $(98,9 \%)$, como era esperado para o teste $5,6,14,19$.

O estudo do comportamento dos testes sorológicos foi realizado pela aplicação do teste estatístico $Q$ de Cochran. Obtivemos que os testes comportaram-se diferentemente entre si $(p<0.05)$ e, pela análise $2 \times 2$ (teste de McNemar) dos testes concluimos que o melhor teste para diagnóstico da neurocisticercose foi o teste ELISA, seguido das reaçōes de IF e HA que comportaram-se igualmente.

Considerando que a RFC ainda é o teste mais difundido quando se investiga a neurocisticercose $\mathrm{e}$, ainda, que somente reagentes imunológicos para a realização das $R F C$ e RIF são correntemente encontrados no comércio, sugerimos que também a RHA e principalmente o teste ELISA, sejam empregados como auxílio no diagnóstico e em possiveis levantamentos epidemiológicos, para que possamos avaliar a real prevalência da neurocisticercose em nosso meio.

\section{SUMMARY}

Comparative study of serological tests in immunological diagnosis for neurocysticercosis
Four immunological techniques were evaluated for the detection of antibodies to Cysticercus cellulosae in cerebrospinal fluid (CSF): complement fixation test (CF), passive haemmagglutination test (PHA), indirect immunofluorescence test (IF) and the enzyme-linked immunosorbent assay (ELISA). One-hundred twenty-five CSF from patients with confirmed neurocysticercosis and 94 CSF from a control group (60 from patients suffering from neuro logical disorders other than neurocysticerco. sis and 34 from presumably healthy individuals) were assayed. The sensitivity and specificity of the tests were determined, which were, $48.0 \%$ and $90.4 \%$ for CF; $888 \%$ and 96.8\% for PHA; $87.2 \%$ and $98.9 \%$ for IF, and 97.6\% and 98.9\% for ELISA, respectively. There were significative differences among the tests and these allowed to conclude that the best immunodiagnostic test for neurocysticer. cosis was ELISA, followed by PHA and IF tests.

\section{AGRADECIMENTOS}

Agradecemos aos Dr. Aluizio de Barros Barreto Machado e Dr. Gilberto Eduardo Bassi pelas amostras de líquido cefalorraquiano.

\section{REIERENGIAS BIBLIOGRAFICAS}

1. BASST, G. E; CAMARGO, M. E.; BITTENCOURT, J. M. T. \& GUARNIERE, D. B. - Reação de imuno. fluorescência com antígenos de Çsticercus cellulosae no líquido cefalorraqueano. Neurobiologia, 42: 165-167, 1979 .

2. BASSI, G. E.; CAMARGO, M. E.; EITTENCOURT, J. M. T. \& CERQUEIRA, F. E. C. - Comparaçăo entre as reaçōes de fixaçăo de complemento e imunofluorescência em líquidos cefalorraqueanos. Neurobiologia, 42: $231-238,1979$.

3. BIAGI, F. F.; NAVARRETE, F; PINA, A. P.; SANTIAGO, A. M. \& TAPIA, L. - Estudio de tres reacciones serológicas en el diagnóstịco de la cisticercosis. Rev. mêd. Hosp. gen. (Mêx.); 25: 501-508, 1961.

4. BRADFORD, M. M. - A rapid and sensitive method for the quantitation of microgram quantities of protein utilizing the principle of protein dye binding. Analyt. Biochem., 72: 248-254, 1976.

5. COSTA, J. M.; FFRRFIRA, A. W.; MAKINO, M. M. \& CAMARGO, M. E. - Spinal fluid immunoenzimatic assay (ELISA) for neurocysticercosis. Rev. Inst. Med. trop. S. Paulo, 24: 337-341, 1982: 
PIALARISSI, C. S. de M.; VAZ, A. J.; SOUZA, A. M. C. de; NAKAMURA, P. M.; CAMARgo, E. D.; SILVA, M. V. \& UEDA, M. - Estudo comparativo de testes sorológicos no diagnóstico imunologico da neurocisticercose. Inst. Med. trop. São Paulo, 29:367-373, 1987.

F. DIWAN, A. R.; COKER-VANN, M.; BROWN, P.; SUBIANTO, D. B.; YOLKEN, R.; DESOWITZ, R.; ESCO. BAR, A.; GIBBS, C. J. \& GAJDUSEK, D. C. - Enzyme-linked immunosorbent assay (ELISA) for the detection of antibody to cysticerci of Taenia solium. Amer. J. trop. Med. Fyg., 1: 364-369, 1982.

7. FERREIRA, A. P.; COSTA, J. M.; MINEO, J. R.; COSTA, M. C. \& GONCALVES, M. R. F. - Estudo de dois diferentes extratos antigênicos de Cysticercus cellulosae na pađronização da microtécnica da reação de fixação de complemento para a pesquisa de anticorpos na neurocisticercose. Rev. Soc. bras. Med. trop., 20 (suplemento): 124-125, 1987.

8. GABAI, G. B. \& REIS-FHHO, J. B. - Contribuição ao estudo da reação de fixação de complemento para cisticercose no soro sanguineo. Rev. paul. Med. 100: $16-19$, 1982 .

9. GALEN, R. S. \& GAMBINO, S. R. - Beyond nor mality: the predictive value and efficiency of medical diagnosis. New York, John Wiley, 1975. 235p.

10. GONZATEZ-BARRANCO, D; SANDOVAL-ISLAS, M. E. \& TRUJILLO-VALDES, V. M. - Reacción de inmúnofluorescencia, indirecta en cisticercosis. Arch. invest. méd. (Méx.), 9: 51-58, 1976.

11. IMAI, M.; YAMASHITA, Y.; MIYAKAWA, Y. \& MAYUMI, M. - Haemagglutination inhibition assay of the common determinants and subspecificities of Australia antigen. Immunology, 27: 871-878, 1974.

12. LANGE, O. - Síndrome liquórica da cisticercose encefalomeningea. Rev. Neurol. Psiquiat. S. Paulo, 6: $35-48,1940$.

13. LivRamento, J. A. - Contribuiçăo de reaçōes de imunofluorescência no liquido cefalorraquiano ao es- tudo da neurocistcercose. Arch. Neuro-psiquiat. (S. Paula), 39: 261-278, 1981.

14. LivRaMento, J. A.; COSTA, J. M.; MACHado, L. R.; NOBREGA, J. P. S. \& SPINA-FRANÇA, A. ELISA (IgG e IgM) no LCR \& soro na neurocisticer cose em tratamento com praziquantel. Arch. Neuro. psiquiat. (S. Paulo), 43: 267-274, 1985.

15. Machado. A. J.; Camargo, M. E. \& HOSHINO, S. - Reação de imunofluorescência para cisticercose com particulas de Cysticercus cellulosae fixadas a lâminas de microscopia. Rev. Soc. bras. Met. trop., 7: $181-183,1973$.
16. MAHAJAN, R. C.; CHITKARA, N. L. \& CHOPRA, S. - Evaluation of cysticercous and adult worm ant gens in serodiagnosis of cysticercosis. Indian J. med. Res., 62: 1310-1313, 1974.

17. MARTINEZ-CAIRO, S.; RUTZ-MARIAS, C.; LOPESROMAN, M. \& MATEOS-GOMEZ, H. - Usefulness of concentrated CSF haemagglutination technic for the diagnosis of cerebral cysticercosis. Arch. invest. méd. (Méx.), 11: 347-359, 1980.

18. MILLER, B. L.; STAUGAITIS, S. M.; TOURTELLOTTE, W. W.; SHAPSHAK, P.; GOLDFERG, M.; HEINER, D. \& WEIL, M. — Intra-bloodbrain barrier IgG synthesis in cerebral cysticercosis. Axch. Neurol. (Chic.), 42: 782-784, 1985.

19. MOHAMMAD, I. N.; HEINER, D.; MULLER, B. L.; GOLDBERG, M. \& KAGAN, I. G. - Enryme-linked immunosorbent assay for the diagnosis of cerebral cysticercosis. J. clin. Microbiol., 20: 775-779, 1984.

20. MASCIMENTO, ש. \& MAYRINK, W. - Avaliaçäo de antígenos de Cysticercus cellulosae no imunodiagnós. tico da cisticercose humanà pela hemaglutinaçâo indireta. Rev. Inst. Med. trop. S. Paulo, 26: 289-294, 1984.

21. NIETO, D. - Cysticercosis of the nervous sistem. Diagnosis by mean of spinal fluid complement fixation test. Neurology (Minneap.), 6: 725-738, 1965.

22. OBERHAUSER, E. \& WEINSTFIN, V. — Estudio comparativo de líquido cefalorraquídeo y sangre en luies e cisticercosis cerebral. Acta neurol. lat.-amer., 14: 74-82, 1968

23. PAUL, J. R. \& WHITE, G. - Serological epidemiology. London, Academic Press, 1973. 235 p.

24. REIS-FILHO, J. B.; REIS, J. B. \& BEI, A. - A reaçăo de fixação de complemento no diagnóstico da neurocisticercose. Neurobiologia, 488: 227-232, 1985.

25. SCOTT, T. A. \& MELVIN, E. H. - Determination of dextran with antrone. Analyt. Chem., 25: 1656* $1661,1953$.

26. SIEGEL, S. - Estatistica não paramétrica para as ciências do comportamento. Rio de Janeiro, McGrawHill, 1975. 350 p.

Recebido para publicação em 29/9/87. 